\title{
OPTIMIZATION OF MACHINING PARAMETERS IN WIRE EDM OF EN24 STEEL
}

\author{
S. PRABU ${ }^{1}$, K. KARTHIK ${ }^{2}$, J. VEERENDRA RAYUDU ${ }^{3} \&$ D. GOKULA KRISHNAN ${ }^{4}$ \\ ${ }^{1,2}$ Assistant Professor, Department of Mechanical Engineering, Veltech Dr. RR \& \\ Dr. SR University, Avadi, Chennai, Tamil Nadu, India \\ ${ }^{3,4} U G$ Scholar, Department of Mechanical Engineering, Veltech Dr. RR \& \\ Dr. SR University, Avadi, Chennai, Tamil Nadu, India
}

\begin{abstract}
This objective of the research work is to obtain better surface finish and higher MRR for EN24 steel by optimizing various process parameters affecting the machining conditions with the assistance of Grey-Taguchi quality engineering. $L_{18}$ orthogonal array $(\mathrm{OA})$ was chosen and 18 experiments were conducted by varying the process parameters at various levels. Analysis of variance was used to find the contribution of each input parameter.

KEYWORDS: WEDM, MRR, $R_{a}$, Grey-Taguchi \& ANOVA
\end{abstract}

Received: Oct 01, 2017; Accepted: Oct 20, 2017; Published: Nov 16, 2017; Paper Id.: IJMPERDDEC201740

\section{INTRODUCTION}

EDM is an unconventional machining process, metal removal is done by the erosion of the spark between the electrode and work piece. In wire EDM a conductive brass wire is used as the electrode and de-ionized water is used as the medium [1]. Intricate parts and difficult to machine materials can be machined easily using WEDM. The selection of input parameters for obtaining larger MRR and good surface finish is done using Taguchi - Grey Relational Analysis, which is a multi objective optimization technique [2].

Ko-Ta Chiang et al (2006), in their paper "modeling and analysis of the rapidly resolidified layer of SG cast iron in the edm process through the responsive surface methodology", observed the changes occurring in spheroidal graphite due to wire edm. The rapidly re-solidified layer is formed by the re-solidification of residual molten metal on the machined surface, during the electric discharge machining process. The factors of second phase considered were quantity, diameter and area fraction of spheroidal graphite particle. The performance of rapidly resolidified layer in terms of the layer thickness and ridge density were the response variables investigated. Experimental plan was performed by a standard rsm design called a central composite design (CCD). The results of analysis of variance (ANOVA) indicated that, the proposed mathematical model could adequately describe the performance within the limits of the factors being studied. Their conclusions reveal that, quantity and area fraction of graphite particle are the most influential factors, on layer thickness and ridge density [8].

Bert Lauwers et al (2006), described the influence of composition and grain size (coarse, micron) of WCbased cermets on manufacturability by wire-EDM. It was shown that, the cutting rate decreases with increasing WC-grain size, which can be explained mainly by the change in thermal conductivity of the material. Finally, the experiment showed that for all investigated materials, the WEDM material removal mechanism is mainly melting, while other mechanisms like spelling have not been recognized [4]. 
Juhr et al (2004), explored improved cemented carbide properties after wire edm, by pulse shaping. Their research was aimed at developing an optimal process energy source, that produces improved material properties after wedm. Their studies showed that, it was important to use the correct parameter selection for main-cut and post-cut. Deterioration in the material properties by processing with high energy pulses can be corrected only by a limited extent in post cut. The primary actuating variable of pulse was pulse duration i.e., with pulse duration less than 500ns higher current magnitudes can also be used without problems. Through the use of new process energy source increase of bending strength of average 30\% could be achieved. Simulation of the pulse wave forms and how the thermal load of the cut surface can be reduced, and the technical conditions could be adapted to a particular application. A comparison of an is energetic equal pulse regimes with increasingly shortened discharge durations did not show an improvement of the bending fraction stress of a main cut, with a pulse energy of $3.6 \mathrm{~mJ}[6]$.

Mu-Tian Yan et al (2004), explored about accuracy improvement of wire edm, by real-time wire tension control. A closed loop wire tension control system for a wire edm machine was presented, to improve the machining accuracy. Dynamic models of the wire feed control apparatus and wire tension control apparatus were derived, to analyze and design the control system. PI controller and one step adaptive controller were employed, to investigate the dynamic performance of the closed loop wire tension control system. Experimental results demonstrated that, the geometrical contour error of corner cutting and the wash out of cliff edge, measured along the thickness of the work piece could be reduced to 50 to $40 \%$, respectively. This method contributed to better corner accuracy and vertical straightness [11].

\section{TAGUCHI DESIGN OF EXPERIMENTS}

Design of experiments was conducted by using Minitab software and the based on varying the process parameters, which affect the machining process, to obtain the required quality characteristics. The process parameters are known as factors, which influence the nature of these response variables.

The factors and levels can be tabulated as shown in Table 1

Table 1: Factors and Levels

\begin{tabular}{|l|l|c|c|c|}
\hline Symbol & \multicolumn{1}{|c|}{ Control Factors } & Level 1 & Level 2 & Level 3 \\
\hline A & Dielectric pressure & Low & High & \\
\hline B & Wire feed rate $(\mathrm{m} / \mathrm{min})$ & 5 & 6 & 7 \\
\hline C & Wire tension $(\mathrm{g})$ & 600 & 700 & 850 \\
\hline D & Pulse on time $(\mu \mathrm{s})$ & 4 & 5 & 6 \\
\hline E & Pulse off time $(\mu \mathrm{s})$ & 5 & 6 & 7 \\
\hline F & Gap current $(\mathrm{amps})$ & 5 & 3 & 1 \\
\hline G & Gap voltage $(\mathrm{V})$ & 45 & 55 & 65 \\
\hline
\end{tabular}

\section{RESULTS AND DISCUSSIONS}

Experiments were conducted as per the $\mathrm{L}_{18}\left(2^{1} * 3^{7}\right)$ orthogonal array, assigning various values of the levels to the process parameters. After individual experiments, for a set of values were conducted on EN24 steel for a size of $150 \times 100 \times 27 \mathrm{~mm}^{3}$. The experimental results were tabulated in Table 2 . 
Table 2: $\mathrm{L}_{18}\left(2^{1} * 3^{7}\right)$ Orthogonal Array with Responses

\begin{tabular}{|c|c|c|c|c|c|c|c|c|c|}
\hline \multirow{2}{*}{ EXPERIMENT NO } & \multicolumn{7}{|c|}{ CONTROL FACTORS } & \multicolumn{2}{|c|}{ RESPONSES } \\
\hline & $\mathbf{A}$ & B & $\mathbf{C}$ & D & $\mathbf{E}$ & $\mathbf{F}$ & $\mathbf{G}$ & MRR (g/min) & $\mathbf{R a}(\mu \mathrm{m})$ \\
\hline 1 & Low & 5 & 600 & 4 & 5 & 5 & 45 & 0.1011 & 3.0745 \\
\hline 2 & Low & 5 & 700 & 5 & 6 & 3 & 55 & 0.0866 & 2.824 \\
\hline 3 & Low & 5 & 850 & 6 & 7 & 1 & 65 & 0.0325 & 1.236 \\
\hline 4 & Low & 6 & 600 & 4 & 6 & 3 & 65 & 0.0649 & 2.4935 \\
\hline 5 & Low & 6 & 700 & 5 & 7 & 1 & 45 & 0.0397 & 2.2525 \\
\hline 6 & Low & 6 & 850 & 6 & 5 & 5 & 55 & 0.0974 & 3.0085 \\
\hline 7 & Low & 7 & 600 & 5 & 5 & 1 & 55 & 0.0469 & 2.433 \\
\hline 8 & Low & 7 & 700 & 6 & 6 & 5 & 65 & 0.1046 & 3.298 \\
\hline 9 & Low & 7 & 850 & 4 & 7 & 3 & 45 & 0.0686 & 2.4825 \\
\hline 10 & High & 5 & 600 & 6 & 7 & 3 & 55 & 0.1119 & 3.518 \\
\hline 11 & High & 5 & 700 & 4 & 5 & 1 & 65 & 0.0361 & 1.838 \\
\hline 12 & High & 5 & 850 & 5 & 6 & 5 & 45 & 0.1227 & 3.789 \\
\hline 13 & High & 6 & 600 & 5 & 7 & 5 & 65 & 0.1155 & 3.685 \\
\hline 14 & High & 6 & 700 & 6 & 5 & 3 & 45 & 0.0794 & 2.7535 \\
\hline 15 & High & 6 & 850 & 4 & 6 & 1 & 55 & 0.0289 & 1.1675 \\
\hline 16 & High & 7 & 600 & 6 & 6 & 1 & 45 & 0.0433 & 2.2605 \\
\hline 17 & High & 7 & 700 & 4 & 7 & 5 & 55 & 0.1083 & 3.1585 \\
\hline 18 & High & 7 & 850 & 5 & 5 & 3 & 65 & 0.0938 & 2.9225 \\
\hline
\end{tabular}

GRA converts the multiple response process optimization problems into a single response optimization situation, with the objective function of an overall grey relational grade. Table.3 shows the grey relation coefficient and grey relational grade for each experiment, using the $\mathrm{L}_{18}\left(2^{1} * 3^{7}\right)$ orthogonal array. The higher grey relational grade reveals that, the corresponding experimental result is closer to the ideally normalized value. Experiment 12 has the best multiple performance characteristic, among 18 experiments, because it has the highest grey relational grade shown in Table 3 and Figure 4.

Table 4: Grey Relation Co-Efficient and Grey Relational Grades

\begin{tabular}{|c|c|c|c|c|c|c|c|c|c|c|}
\hline \multirow{2}{*}{ EXP. NO } & \multicolumn{9}{|c|}{ CONTROL FACTORS } & \multicolumn{2}{c|}{$\begin{array}{c}\text { GREY RELATION } \\
\text { CO- EFFICIENT }\end{array}$} & \multirow{2}{*}{$\begin{array}{c}\text { GREY } \\
\text { GRADE }\end{array}$} \\
\cline { 2 - 11 } & A & B & C & D & E & F & G & MRR & Ra & \\
\hline 1 & Low & 5 & 600 & 4 & 5 & 5 & 45 & 0.78874 & 0.73801 & 0.76338 \\
\hline 2 & Low & 5 & 700 & 5 & 6 & 3 & 55 & 0.67478 & 0.66694 & 0.67086 \\
\hline 3 & Low & 5 & 850 & 6 & 7 & 1 & 65 & 0.35241 & 0.34446 & 0.34844 \\
\hline 4 & Low & 6 & 600 & 4 & 6 & 3 & 65 & 0.53164 & 0.58451 & 0.55808 \\
\hline 5 & Low & 6 & 700 & 5 & 7 & 1 & 45 & 0.39049 & 0.53092 & 0.46071 \\
\hline 6 & Low & 6 & 850 & 6 & 5 & 5 & 55 & 0.75791 & 0.71846 & 0.73819 \\
\hline 7 & Low & 7 & 600 & 5 & 5 & 1 & 55 & 0.42913 & 0.57059 & 0.49986 \\
\hline 8 & Low & 7 & 700 & 6 & 6 & 5 & 65 & 0.81916 & 0.80921 & 0.81419 \\
\hline 9 & Low & 7 & 850 & 4 & 7 & 3 & 45 & 0.55424 & 0.58196 & 0.56810 \\
\hline 10 & High & 5 & 600 & 6 & 7 & 3 & 55 & 0.88697 & 0.88804 & 0.88751 \\
\hline 11 & High & 5 & 700 & 4 & 5 & 1 & 65 & 0.37143 & 0.44863 & 0.41003 \\
\hline 12 & High & 5 & 850 & 5 & 6 & 5 & 45 & 1 & 1 & 1 \\
\hline 13 & High & 6 & 600 & 5 & 7 & 5 & 65 & 0.92279 & 0.95484 & 0.93882 \\
\hline 14 & High & 6 & 700 & 6 & 5 & 3 & 45 & 0.62420 & 0.64837 & 0.63629 \\
\hline 15 & High & 6 & 850 & 4 & 6 & 1 & 55 & 0.33333 & 0.33333 & 0.33333 \\
\hline 16 & High & 7 & 600 & 6 & 6 & 1 & 45 & 0.40971 & 0.53262 & 0.47117 \\
\hline 17 & High & 7 & 700 & 4 & 7 & 5 & 55 & 0.85275 & 0.76381 & 0.80828 \\
\hline 18 & High & 7 & 850 & 5 & 5 & 3 & 65 & 0.72913 & 0.69389 & 0.71151 \\
\hline
\end{tabular}




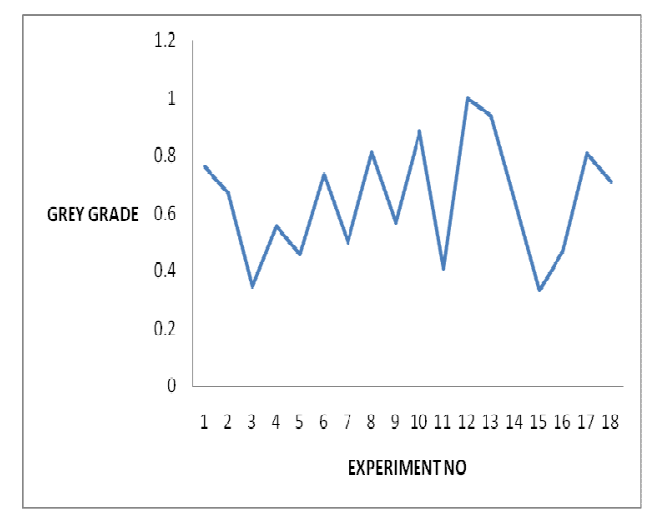

Figure 1: Grey Relational Grades for Maximum MRR and Minimum Ra

Figure 1, shows the Grey relational grades for maximum MRR and Minimum Ra. Since, the experimental design is orthogonal; it is possible to separate out the effect of each machining parameter on the grey relational grade, at different levels. For example, the mean of the grey relational grade for the Dielectric pressure at levels 1and 2 can be calculated by averaging the grey relational grade for the experiments 1 to 8 , and 9 to 18 , respectively. The mean of the grey relational grade for each level of the other machining parameters can be computed in a similar manner.

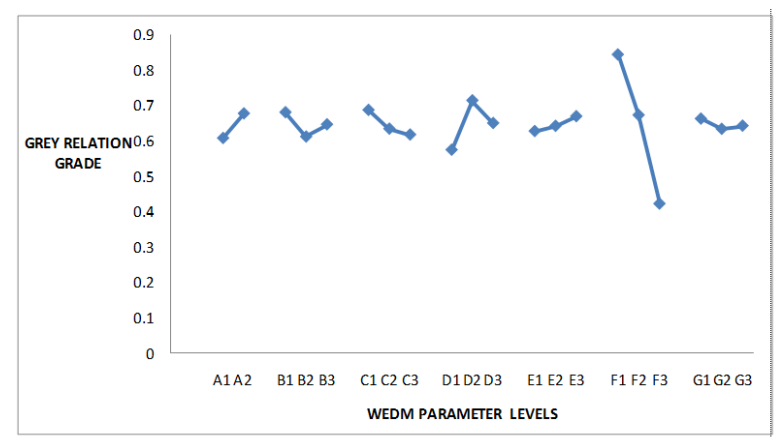

Figure 6.2: Response Graph of Average Grey Relational Grade

\section{ANALYSIS OF VARIANCE (ANOVA)}

The results of the ANOVA are shown in Table 3 and from the graphical representation it is clear that, average gap current is the major influencing factor, contributing $90.007 \%$ to MRR, followed by pulse-on time contributing $4.361 \%$, pulse-off time contributing $0.277 \%$ and Wire Feed contributing 1.654\%, Dielectric pressure contributing 1.013\%, Wire tension contributing $1.552 \%$ and gap voltage contributing $0.108 \%$.

Table 3: Influence of Various Parameters on MRR

\begin{tabular}{|l|c|c|c|c|c|}
\hline \multicolumn{1}{|c|}{ PARAMETERS } & SUM of SQUARES & VARIANCE & DOF & $\begin{array}{c}\text { F Test } \\
\text { Values }\end{array}$ & CONTRIBUTION \% \\
\hline DIELECTRIC PRESSURE & 3.101 & 3.101 & 1 & 4.924 & 1.013 \\
\hline WIRE FEED & 5.061 & 2.5305 & 2 & 4.018 & 1.654 \\
\hline WIRE TENSION & 4.747 & 2.3735 & 2 & 3.769 & 1.552 \\
\hline PULSE ON TIME & 13.343 & 6.6715 & 2 & 10.593 & 4.361 \\
\hline PULSE OFF TIME & 0.847 & 0.4235 & 2 & 0.6724 & 0.277 \\
\hline AVERAGE GAP CURRENT & 275.422 & 137.711 & 2 & 218.658 & 90.007 \\
\hline GAP VOLTAGE & 0.331 & 0.1655 & 2 & 0.263 & 0.108 \\
\hline ERROR & 3.149 & 0.6298 & 5 & & 1.029 \\
\hline \multicolumn{1}{|c|}{ TOTAL } & & & & \\
\hline
\end{tabular}


The results of the ANOVA are represented in graphical form and from the graphical representation it is clear that average gap current is the major influencing factor contributing $90.007 \%$ to MRR, followed by pulse-on time contributing 4.361\%, pulse-off time contributing 0.277\% and Wire Feed contributing 1.654\%, Dielectric pressure contributing 1.013\%, Wire tension contributing $1.552 \%$ and gap voltage contributing $0.108 \%$.

Table 4: Influence of Various Parameters on Surface Roughness

\begin{tabular}{|c|c|c|c|c|c|}
\hline PARAMETERS & SUM of SQUARES & VARIANCE & DOF & $\begin{array}{c}\text { F Test } \\
\text { Values }\end{array}$ & CONTRIBUTION \% \\
\hline DIELECTRIC PRESSURE & 0.141 & 0.141 & 1 & 0.0536 & 0.0994 \\
\hline WIRE FEED & 3.428 & 1.714 & 2 & 0.6509 & 2.4165 \\
\hline WIRE TENSION & 15.179 & 7.589 & 2 & 2.8823 & 10.704 \\
\hline PULSE ON TIME & 15.893 & 7.947 & 2 & 3.0182 & 11.2034 \\
\hline PULSE OFF TIME & 0.815 & 0.408 & 2 & 0.1549 & 0.5745 \\
\hline AVERAGE GAP CURRENT & 92.78 & 46.390 & 2 & 17.6187 & 65.403 \\
\hline GAP VOLTAGE & 0.458 & 0.229 & 2 & 0.0869 & 0.3228 \\
\hline ERROR & 13.165 & 2.633 & 5 & & 9.2803 \\
\hline TOTAL & 141.859 & & & & 100 \\
\hline
\end{tabular}

\section{CONFIRMATION EXPERIMENT}

Table 5 shows the comparison of the experimental results using the initial (A2B1C3D2E2F1G3) and optimal (A2 B1C1D2E3F1G1) WEDM parameters on EN24 steel. The response values obtained from the confirmation experiment are $\mathrm{MRR}=0.1316 \mathrm{~g} / \mathrm{min}$ and $\mathrm{Ra}=3.347 \mu \mathrm{m}$. The Material Removal Rate shows an increased value of $0.1227 \mathrm{~g} / \mathrm{min}$ to 0.1316 $\mathrm{g} / \mathrm{min}$ and the Surface Roughness shows a reduced value of $3.789 \mu \mathrm{m}$ to $3.347 \mu \mathrm{m}$ respectively. The corresponding improvement in Material Removal Rate and Surface Roughness were 7.25\%and $11.66 \%$ respectively.

Table 5: Optimization Results of OA $\mathrm{L}_{18}\left(2^{1} * 3^{7}\right)$ Vs Grey Theory Design

\begin{tabular}{|l|c|c|}
\hline \multirow{2}{*}{} & \multicolumn{2}{|c|}{ Optimal Process Parameters } \\
\cline { 2 - 3 } & Orthogonal Array & Grey Theory Design \\
\hline Level & A2B1C3D2E2F1G3 & A2 B1C1D2E3F1G1 \\
\hline $\mathrm{MRR}(\mathrm{g} / \mathrm{min})$ & 0.1227 & 0.1316 \\
\hline $\mathrm{Ra}(\mu \mathrm{m})$ & 3.789 & 3.347 \\
\hline
\end{tabular}

The results of the ANOVA are represented in graphical form and from the graphical representation it is clear that, average gap current is the major influencing factor contributing $65.403 \%$ to MRR, followed by pulse-on time contributing $11.2034 \%$, pulse-off time contributing 0.5745\% and Wire Feed contributing $2.4165 \%$, Dielectric pressure contributing $0.0994 \%$, Wire tension contributing $10.704 \%$ and gap voltage contributing $0.3228 \%$.

\section{CONCLUSIONS}

- The optimal 'process parameters' based on Grey Relational Analysis for the Wire-Cut EDM of EN24 steel include a high Dielectric pressure with a wire feed rate of $5 \mathrm{~m} / \mathrm{min}$ and wire tension of $600 \mathrm{~g}, 5 \mu \mathrm{s}$ pulse on time, pulse off time of $7 \mu \mathrm{s}$, Average Gap current of $5 \mathrm{~A}$ and Gap voltage of $45 \mathrm{~V}$.

- While applying the Grey-Taguchi method, The Material Removal Rate shows an increased value of $0.1227 \mathrm{~g} / \mathrm{min}$ to $0.1316 \mathrm{~g} / \mathrm{min}$ and the Surface Roughness shows a reduced value of $3.789 \mu \mathrm{m}$ to $3.347 \mu \mathrm{m}$ respectively, which are positive indicators of efficiency in the machining process. 


\section{REFERENCES}

1. Udaya Prakash, J, Ramkumar, Moorthy, TV \& Anburose, S (2015), 'Parametric Optimization of Wire-EDM on AISI H13 Tool Steel', International Journal of Applied Engineering Research, vol.10 no.68, pp. 472-475.

2. Udaya Prakash, J, Milton Peter, J \& Moorthy, TV (2012), 'Optimization of Wire EDM Process Parameters of Aluminium Alloy/Flyash/Boron Carbide Hybrid Composites', International Review of Mechanical Engineering, vol. 6, no.3, pp. 449-455.

3. Bert Lauwers, Weidong Liu, Wesley Eerasts (2006) 'Influence of the composition of wc-based cermets on manufacturability by Wire-EDM', journal of manufacturing processes vol.8/No.2, pp. 1707-1720.

4. BiingHwa Yan, Hsien Chung Tsai, Fuang Yuan Huang, Long Chorng Lee (2005) 'Examination Of Wire Electrical Discharge Machining $\mathrm{Of} \mathrm{Al}_{2} \mathrm{O}_{3}$ p/6061Al Composites', International Journal of Machine Tools \& Manufacture vol. 45, pp. 251-259.

5. Rahul Davis, Optimization of Surface Roughness in Wet Turning Operation of EN24 Steel, International Journal of Mechanical and Production Engineering Research and Development (IJMPERD), Volume 2, Issue 3, September 2012, pp. 2836

6. El-Taweel. T. A, Hewidy. M. S, El-Safty. M.F (2005) 'Modeling the machining parameters of wire electric discharge machining of inconel 601 using rsm', Journal of material processing technology Vol. 169, pp. 328-336.

7. Juhr. H, Schulze. H. P, Wollenburg. G, Kunanz. K (2004) 'Improved cemented carbide properties after wire EDM by pulse shaping', Journal of material processing technology Vol. 149, pp. 178-183.

8. Kanlayasiri. S, Boonmung. S (2007) 'An investigation on effects of wire EDM machining parameters on surface roughness of newly developed DC53 die steel', Journal of materials processing technology Vol. 187, pp. 26-29.

9. Ko-Ta Chiang, Fu-Ping Chang, De-Chang Tsai(2006) 'Modeling and analysis of rapidly resolidified layer of SG cast iron in the EDM process through responsive surface methodology', Journal of Materials Processing Technology Vol. 182, pp. 525533.

10. Liao. Y. S, Huang. J. T, Chen. Y. $H$ (2003) 'A study to achieve a fine surface finish in Wire EDM'-Journal of material processing technology Vol. 149, pp. 165-171.

11. Muthu Kumar V, Suresh Babu A, Venkatasamy R and Raajenthiren M (2010) 'Optimization of the WEDM Parameters on Machining Incoloy800 Super alloy with Multiple Quality Characteristics, International Journal of Engineering Science and Technology Vol. 2(6), pp. 1538-1547.

12. Mu-Tian Yan, Pin-Hsum Huang(2004) 'Accuracy improvement of wire edm by real time wire tension control', Journal of Machine tools and Manufacture Vol. 44, pp. 807-814. 